\title{
De Roma a Angostura: acercamiento al pensamiento político de Simón Bolívar a través de sus escritos durante las fases iniciales del proceso de Independencia Primera parte (1805-1813)*
}

\author{
Diego Andrés Bernal Botero* \\ Recibido: 30 de agosto de 2016 \\ Enviado a pares evaluadores: 1 de septiembre de 2016 \\ Aprobado por pares evaluadores: 12 de octubre de 2016 \\ Aprobado por Comité Editorial: 8 de noviembre de 2016 \\ DOI: 10.22395/csye.v5n10a8
}

\section{RESUMEN}

El presente texto pretende acercarse al pensamiento político de Simón Bolívar a través del análisis de sus principales documentos del período comprendido entre 1805 y 1819, así como del contexto en medio del que estos fueron producidos, labor que, si se extendiera a la totalidad de los mismos, difícilmente podría ser concluida en un corto lapso de tiempo y mucho menos con el fin de la publicación de un artículo como el que nos involucra en esta oportunidad.

Para esta primera entrega, seguiremos a Simón Bolívar desde su nacimiento, formación y despuntar político, hasta ser elevado y reconocido como El Libertador, en medio de su apoteósica recepción en Caracas tras la exitosa Campaña Admirable, apenas unos meses antes de su estrepitosa caída y los años aciagos que siguieron a ella, tema que abordaremos en la segunda parte de este escrito; un recorrido por sus victorias y sus derrotas a lo largo de este período, las mismas que contribuyeron a formar su carácter y lo hicieron sobresalir entre sus compañeros de lucha por su abnegación y coraje.

Palabras clave: Simón Bolívar; pensamiento político; Independencia; Venezuela; Nueva Granada.

\footnotetext{
Esta reflexión inédita surge de un trabajo que en 2008, aún como estudiante de la Maestría en Historia de la Universidad Nacional de Colombia-sede Medellín, efectué para la asignatura Problemas de la Transición entre el Antiguo Régimen Colonial y la Modernidad: El Nuevo Reino de Granada, dirigida por el docente José Manuel Serrano Álvarez. Muchos años han pasado, pero desde el ejercicio docente permanente, se ha ido depurando la información aquí ofrecida.

** Comunicador social-periodista de la Universidad Pontificia Bolivariana (2003), magíster en Historia de la Universidad Nacional de Colombia, sede Medellín (2013) y candidato a doctor en Historia de la Universidad Pablo de Olavide de Sevilla, España. En la actualidad se desempeña como docente interno en el Programa de Historia de la Universidad Pontificia Bolivariana y de Cátedra en el Departamento de Historia de la Universidad de Antioquia, donde hace parte del Grupo de Estudios Interdisciplinares en Historia General de la Facultad de Ciencias Sociales. Es, además, Secretario Permanente de la Red Iberoamericana de Valoración y Gestión de Cementerios Patrimoniales y Vocal del Capítulo Antioquia de la Asociación Colombiana de Historiadores. Correo electrónico: maverickbernal@yahoo.es
} 


\section{From Rome to Angostura: a study of Simon Bolivar's political thought based on his writings during the initial phases of the Independence process (first period, 1805-1813).}

\section{ABSTRACT}

This article approaches the political thought of Simón Bolívar through an analysis of his most important documents written in the period 1805-1819, and of the context in which they were written. The article follows Bolívar's life, from his birth, through his education and political success up to his achieving the status of the Liberator at his glorious reception in Caracas after the successful Admirable Campaign, just

a few months before his spectacular fall from grace and the inglorious years that followed. The article traces his victories and defeats throughout this period, focusing on how they formed his character and contributed to his exaltation amongst his comrades for his self-sacrifice and courage.

Keywords: Simón Bolívar; political thought; Independence; Venezuela; New Granada. 


\section{Introducción}

Escribir acerca del pensamiento político de Bolívar puede parecerles a muchos llover sobre mojado, al contarse por decenas los trabajos que han abordado la vida y obra de El Libertador, ensalzando sus aciertos o criticando sus planteamientos y posturas, situación apenas obvia al reconocer las dimensiones del personaje y su connotación en la historia nacional y latinoamericana. Sin embargo, más allá de los datos biográficos y las discusiones historiográficas clásicas y actuales, en este artículo hemos decidido centrarnos en el análisis de algunas de las ideas políticas que el mismo Bolívar plasmó en los escritos que se le atribuyen en sus fases tempranas, así como en las circunstancias que rodeaban su vida al momento de escribirlos y/o publicarlos.

Desde este punto de vista, hemos seleccionado en general siete de los más importantes textos adjudicados a Bolívar, cuyo análisis aspiramos facilite un corto y limitado acercamiento a su vida y obra temprana, ejercicio que permitirá arrojar un poco de pistas para el posterior análisis de sus ideas e iniciativas de gobierno, una vez los hechos en los que participó y las circunstancias que modelaron este convulso período histórico lo pusieran al frente de los destinos de una amplia zona de la América meridional.

El recorrido planteado para esta primera entrega comienza en Roma, ciudad en la que, de acuerdo con los relatos patrióticos, el joven Simón Bolívar lanzó su primera promesa de liberar a Venezuela y a la América Hispana en general, 'Juramento' que aún no es claro quién se encargó de 'transcribir', pero que como texto comenzó a circular en vida de El Libertador y que desde el siglo XIX es uno de los puntos de partida favoritos para los biógrafos que describen cómo este joven venezolano, viudo y miembro de la aristocracia criolla, decidió dejarlo todo para abrazar las ideas de la libertad.

Pasaremos luego a analizar el primero de los que son considerados como los grandes escritos políticos de Bolívar: el Manifiesto de Cartagena, documento a través del cual, el entonces coronel del ejército cartagenero analizó los factores que en su concepto propiciaron la caída de la Primera República Venezolana, a la par que le lanzó múltiples recomendaciones a la Nueva Granada para que no cayera en los mismos errores y le tendiera una mano a Venezuela para liberarla de nuevo de Monteverde y las tropas leales a la Corona Española, aún sumergida en la profunda crisis que trajo consigo la invasión napoleónica.

Seis meses después, Bolívar, estrenando su título de Brigadier General de los Ejércitos de las Provincias Unidas de la Nueva Granada, lanzó el Decreto de Guerra a Muerte, proclama que transportada al presente podría despertar los más duros comentarios y que en su época suscitó el escalonamiento del con- 
flicto hasta los límites mismos de la barbarie. Esta situación quedó reflejada en la Carta de Jamaica, cuando el propio Bolívar describió a Venezuela como un territorio devastado por la guerra y los padecimientos de un conflicto de la intensidad del que se vivió en sus campos.

Sin embargo, el Decreto de Guerra a Muerte y la eficiente labor de las tropas bolivarianas que avanzaron desde la Nueva Granada a lo largo de la Cordillera Oriental y siguiendo las costas del Lago de Maracaibo coronarían de éxito esta 'Campaña Admirable' que le permitió a Bolívar regresar a su natal Caracas como héroe y caudillo, aclamado bajo el título que usaría por el resto de sus días: el de El Libertador.

La segunda entrega, prevista para un futuro número de esta revista, tendrá como punto de partida el 7 de septiembre de 1814, fecha en la que Bolívar volvió a dejar testimonio de sí mismo a través de su Manifiesto de Carúpano, escrito antes de salir nuevamente derrotado, pero digno, hacia la Nueva Granada. Venezuela había caído por segunda vez, pero Bolívar les escribía a sus habitantes (en especial a los caraqueños) prometiendo nuevas expediciones libertarias, a la par que evaluaba su fracaso, haciendo hincapié en la responsabilidad que les correspondía a los propios venezolanos, quienes se resistieron a dejar de lado su pasado realista, e hicieron infructuosos los intentos del recién nombrado Libertador.

Jamaica fue la sede del que quizá ha sido el escrito político de Bolívar más comentado y analizado a través de los años. La Carta de Jamaica es una cruda radiografía de la América Meridional y sus procesos de independencia, a la par que muchos analistas ven en su autor, a un hombre con capacidades casi proféticas que le permitieron asomarse al futuro y predecir lo que iban a vivir los Estados americanos una vez lograran concluir su independencia, calificativo desmesurado que no por eso deja pasar de largo las evidentes coincidencias entre los planteamientos de aquel Bolívar que escribía desde el exilio y la tozudez de los hechos.

Analizaremos de este texto en particular sus postulados políticos, los cuales iba a seguir construyendo y ajustando Bolívar a lo largo de los años, pero que emergieron en esta ocasión de manera clara, amplia y argumentada, lejos como estaba del mando de tropas o del servicio a cualquier otro jefe patriota, al ser el supuesto destinatario de esta carta una persona frente a la cual el caraqueño sentía la suficiente confianza para expresarse, sin tener que hacer uso del lenguaje políticamente correcto del que hizo gala en la mayoría de sus escritos.

De vuelta al mundo de las acciones militares, revisaremos el polémico decreto de libertad para los esclavos con el que Bolívar buscó acercar a la causa de la 
independencia a uno de los renglones populares más vulnerable, iniciativa que fue condicionada al apoyo efectivo de los nuevos libertos a las causas patrióticas, lo que nos presenta a un personaje que sabía calcular las implicaciones de una acción que lo puso en riesgo frente a la clase social que representaba y que era la que tradicionalmente lo había apoyado, la misma que condenó al olvido buena parte de las iniciativas que, como este decreto bolivariano, fueron desatendidas o solo parcialmente aplicadas hasta la segunda mitad del siglo XIX.

Por último, revisaremos el Discurso de Angostura en el que se aprecia ya a un Bolívar esperanzado en el éxito de la confrontación militar que comenzaba a balancearse a favor de las fuerzas que dirigía. Ejército que se encontraba ya reforzado por la reciente llegada de las armas y los batallones enviados subrepticiamente por Inglaterra, contingente que pasó a conocerse como la Legión Británica.

En este discurso Bolívar actuaba ya como gobernante, postura que le permitió aconsejar a los delegados ante el Congreso de Angostura, así como dar pautas y establecer límites. En este ejercicio argumentativo no solo recurrió a la teoría y los modelos clásicos, sino que tuvo la oportunidad de capitalizar los 8 años y medio de actividad política y militar, si entendemos como su verdadero inicio 'republicano' el mes de agosto de 1810, momento en el que fue comisionado para viajar a Gran Bretaña por la recién conformada Junta Conservadora de los Derechos de Fernando VII, donde entró en contacto con Francisco de Miranda.

A lo largo de este artículo, dividido en dos partes, buscaremos establecer un vínculo hermenéutico con el autor que escribía, dictaba o inspiraba cada uno de los textos analizados, con el fin de comprender las circunstancias que lo envolvían y sus posibles intencionalidades, así como el contexto y los condicionamientos a partir de los que partían para su interpretación los públicos que entraban en contacto con sus escritos.

Sin más preámbulos, iniciemos este recorrido por el pensamiento político de Bolívar a través de sus propios textos. Una excusa válida para darle un vistazo al período de la independencia, en momentos en que continúan planeándose conmemoraciones relacionadas con el bicentenario del proceso que dio fin a la dominación hispana en buena parte de este hemisferio.

\section{Bolívar y sus primeros años}

Coinciden los historiadores clásicos y contemporáneos en que la niñez y la juventud de Bolívar transcurrieron tal y como podría esperarse en la vida de un criollo hijo de una familia prestante, aunque con el tinte de soledad que le correspondía a una persona que quedó huérfana de padre a los 2 años y de madre a los 9. Así 
las cosas, la crianza de Bolívar debió ser compartida entre sus tíos y abuelos, hasta que estos decidieron confiárselo a Simón Rodríguez, quien fue uno de los maestros que más influencia tuvo en su vida, a la par que Andrés Bello.

Nacido en 1783, año en que se confirmó en París la independencia de las antiguas colonias británicas en la América septentrional, Bolívar creció en un mundo en crisis que cambió rápidamente en medio del convulsionado ritmo de las guerras y las revoluciones. Sin embargo, no existen datos de peso que permitan afirmar que a través de sus maestros o por noticias llegadas a Venezuela desde Europa o los Estados Unidos, el joven Bolívar pudiera haber recibido influencias particulares o haya demostrado algún tipo de tendencia que hiciera preludiar el papel que jugaría en la historia, más allá de haber recibido una educación de carácter ilustrado por parte de sus dos maestros.

Su primer acercamiento con la vida militar lo tuvo a los 13 años, cuando ingresó el 14 de enero de 1797 al Batallón de Milicias de Blancos de los Valles de Araguá, antes de trasladarse en 1798 a España a continuar sus estudios, como era común entre los jóvenes miembros de la aristocracia criolla.

Bolívar se casó en Madrid con doña María Teresa Rodríguez del Toro en abril de 1802 y regresó a Venezuela, donde enviudó apenas nueve meses después, lo cual marcó una visible ruptura en el curso 'normal' de la vida de un criollo terrateniente. Fue otro Bolívar el que regresó a Europa en 1803 y el que permaneció en ella hasta 1807. En sus años de travesía, entró en contacto con importantes personajes como el varón Von Humboldt, quien gracias a sus viajes y expediciones científicas conocía al detalle las potencialidades de América. Asimismo, Bolívar presenció la apoteosis de Napoleón, quien se coronó como Emperador de los franceses y extendió su manto de influencia por el continente europeo. Tales hechos y acontecimientos quedaron marcados en lo profundo de su ser, como pudo evidenciarse en muchas de sus actitudes, así al revisar sus escritos el ilustre Corso parezca desapercibido.

Es en esta época cuando se da su viaje a Italia en el que, de acuerdo con las tradiciones historiográficas, el 15 de agosto de 1805 lanzó el Juramento de Roma. Nuestra primera estación en medio de este recorrido.

\section{Juramento de Roma}

Uno de los aspectos en los que coinciden los biógrafos y apologistas de Bolívar es en destacar al Juramento de Roma como el punto de partida de su vida política, pues ven en él las primeras muestras de sus convicciones. De acuerdo con sus postulados, tras este acto simbólico Bolívar comenzó a acariciar un proyecto que lo llevó a las más altas dignidades. 
Más allá de poner en tela de juicio el que Bolívar haya pronunciado elocuentes palabras en la cima del Monte Sacro (o en alguna de las siete colinas romanas, pues existen diferentes interpretaciones, incluida la versión adjudicada a Bolívar de que fue en el Monte Palatino), poco se ha discutido acerca de la veracidad, intencionalidad, autor y época de publicación del documento escrito, aspectos fundamentales a la hora de realizar una correcta crítica de fuentes, a un documento que si bien puede resumir o condensar los aspectos sobresalientes de una proclama lanzada entre amigos en un momento de especial fervor, es prácticamente imposible que se trate de una transcripción literal de lo expresado por un joven Bolívar en estas circunstancias.

Es importante analizar con cuidado y detenimiento el Juramento de Roma, a la par que resultaría interesante ahondar en la solución de los interrogantes anteriormente planteados, en especial el relacionado con el real autor o el transcriptor de la primera versión escrita de este documento, que necesariamente es posterior a la proclama misma, al no tratarse, de acuerdo con la tradición historiográfica, de un discurso preparado con anterioridad.

Basándonos en el documento escrito, del cual es muy importante anotar que hay coincidencia absoluta en cuanto a su contenido, lo que nos ahorra el tener que analizar diferentes versiones o 'Juramentos apócrifos', podemos ver cómo el joven Bolívar realizó un breve recorrido de exaltación, crítica y remembranza de las gestas y desgracias romanas, destacando a la ciudad como cuna de la civilización, pero evidenciando en ella el fracaso de todos los modelos a través de los que se trató de satisfacer una de las principales necesidades del hombre: su libertad.

Fue entonces cuando, de acuerdo con la versión de Simón Rodríguez y transcrita por Manuel Uribe Ángel, Bolívar remató su intervención con una frase que pasó a la historia:

[...] iJuro delante de usted; juro por el Dios de mis padres; juro por ellos!; ijuro por mi honor, y juro por mi Patria, que no daré descanso a mi brazo, ni reposo a mi alma, hasta que haya roto las cadenas que nos oprimen por voluntad del poder español! (Uribe Ángel, 1884, p. 74).

Estas palabras revisten singular importancia, de ser ciertas y exactas, pues Bolívar se estaría adelantando casi un año a la proclama que le lanzó al pueblo venezolano Francisco de Miranda el 2 de agosto de 1806, en medio de su primera campaña independentista, la cual, como se expondrá más adelante, alcanzó pobrísimos resultados.

El Juramento es claro y elocuente, razón por la cual ha sido vital para la historiografía de tipo nacional y para los apologistas de Bolívar el darlo por cierto 
y exacto, toda vez que da tempranas muestras de la firmeza en el carácter del personaje al que se le adjudica y de lo comprometido que se mostraba éste con la causa de la independencia, a pesar de sus recién cumplidos 22 años.

Más allá del debate y las dudas expresadas, el Simón Bolívar que regresó a Caracas a mediados de 1807 era muy distinto al joven viudo que partió en 1803. Cerró su segundo periplo por Europa, pero lo allí visto y aprendido quedó grabado en su pensamiento político a lo largo de su existencia. Faltaba solo una coyuntura especial para pasar a la acción, oportunidad que Bolívar no desaprovechó.

\section{Francisco de Miranda: el precursor de la Independencia}

Francisco de Miranda es, sin lugar a dudas, uno de los más preclaros hijos de la Ilustración que engendró la América meridional, aunque haya sido castigado con el olvido como consecuencia de su fracaso y, hasta cierto punto, de su desafortunado final, en el que Bolívar tuvo mucho que ver.

En su agitada carrera política y militar, Miranda tuvo la oportunidad de acercarse y participar en las confrontaciones que antecedieron a la guerra de independencia norteamericana, territorio al que regresó en su período formativo, y entrando en contacto con lo más selecto de su dirigencia, así como en varias de las batallas que tuvieron lugar tras el estallido de la Revolución francesa, las cuales le valieron el título de Mariscal de Campo del ejército francés, testimonio imborrable de su cercanía con la causa de la libertad que quedó en el Arco del Triunfo, donde se encuentra grabado su apellido.

Aun permaneciendo gran parte de su vida en el exterior, Miranda es considerado el Precursor de la independencia de los países hispanoamericanos, en especial de los que conformaron la antigua Gran Colombia, toda vez que fue el primero en intentar liberarlas del dominio español, iniciativa quijotesca que no solo no coronó con éxito, sino que condujo a la muerte a varios de los románticos expedicionarios multinacionales que lo acompañaron en su infausta tentativa.

De la incursión de Miranda a las costas venezolanas y a la ciudad de Coro, a pesar de su corta duración y exiguos éxitos, quedaron como herencia la existencia del pabellón nacional que comparten las actuales repúblicas de Venezuela, Ecuador y Colombia, así como el propio nombre de Colombia, que se dio a conocer a través del texto que pasó a la historia como la Proclamación de Don Francisco de Miranda, Comandante-General del Exército Colombiano, á los pueblos habitantes del Continente Americo-Colombiano, expedido desde su cuartel general de Coro, el 2 de agosto de 1806. 
A pesar de que él mismo expone en su texto que "... la coyuntura y el tiempo nos parecen sumamente favorables para la Consecución de vuestros designios..." (Miranda, 1806), los habitantes de Venezuela pocos ánimos mostraron frente al recién llegado, quien argumentaba, sin embargo, estar "Obedeciendo a vuestros llamamientos y a las repetidas instancias y clamores de la Patria" (Miranda, 1806). No cabe duda de que Miranda acariciaba un proyecto serio y bien concebido, lo cual le permitió resumir en diez puntos las normas que a partir de su desembarco debían seguir los pueblos a los que aspiraba 'liberar', pero es claro también que la ausencia de una coyuntura verdaderamente propicia lo alejó del cumplimiento de sus metas.

\section{Comienza la Guerpa de Independencia... española}

Esta anhelada coyuntura llegó en el año 1808 cuando se desencadenó en España una serie de acontecimientos que cambiaron para siempre su historia y la de sus posesiones americanas, los mismos que fueron propiciados por la firma del Tratado de Fontainebleu en octubre de 1807, a través del cual se autorizó el ingreso a a los ejércitos napoleónicos a territorio español.

Fue así como el 19 de marzo de 1808 tuvo lugar el Motín de Aranjuez, en el que Carlos IV abdicó a favor de su hijo Fernando VII, reinado que tuvo muy corta duración, al ser conducidos padre e hijo a Bayona, en donde el 5 de mayo del mismo año; Napoleón fue el receptor final del cetro borbónico, para nombrar luego a su propio hermano como soberano de España.

Estas noticias no tardaron en llegar a América, antecediendo incluso al arribo a costas venezolanas del bergantín francés Le Serpent, el cual atracó el 15 de julio de 1808 en el puerto de La Guaira, y que traía consigo delegados de Napoleón, quienes no fueron bien acogidos.

Tras la llegada de noticas relacionadas con la creación de la Junta Central de España, Venezuela comenzó a experimentar estados de agitación interna que no pudieron ser conjurados por su nuevo Capitán General, el Mariscal de Campo Vicente Emperán, y fue así como el 19 de agosto de 1810, el Cabildo de Caracas constituyó una Junta Conservadora de los Derechos de Fernando VII y expulsó de su territorio a las autoridades peninsulares.

Las condiciones estaban dadas y el joven Bolívar comenzó a figurar entre la dirigencia criolla que tomó las riendas de la Junta, siendo comisionado, en compañía de don Andrés Bello y Luis López Méndez, para viajar a Inglaterra en busca de apoyo, territorio en el que entró en contacto por primera vez con Francisco de Miranda. 


\section{Bolivar y Miranda}

Aunque la gestión que adelantaron los tres delegados frente al gobierno británico no alcanzó logros significativos, el encuentro de Bolívar con Francisco de Miranda trajo consigo el retorno de este a Venezuela el 10 de diciembre de 1810. El Precursor gozaba para entonces de admiración y fue bien recibido, convirtiéndose en el primer presidente de la naciente república el 5 de julio de 1811, fecha en la que Venezuela declaró su independencia absoluta de España.

Investido de poderes dictatoriales, Miranda emprendió acciones al poco tiempo contra la ciudad de Valencia, la cual perseveraba en su apoyo a los realistas, gesta militar que se desarrolló el 13 de agosto de 1811 y en la que Bolívar tuvo su bautizo de fuego, siendo ascendido al rango de Coronel. Sin embargo, la situación de Venezuela empeoró rápidamente, registrándose múltiples levantamientos y pugnas regionales que debilitaron al gobierno.

El comienzo del fin de la Primera República de Venezuela se dio ante el arribo del Capitán de Fragata Juan Domingo de Monteverde, quien comenzó acciones bélicas en marzo de 1812 desde la ciudad de Coro, situación que Bolívar juzgó como un acto de debilidad por parte del gobierno de Miranda, como quedó consignado en el Manifiesto de Cartagena.

Escribió Bolívar al respecto:

[...] Las primeras pruebas que dio nuestro gobierno de su insensata debilidad, las manifestó con la ciudad subalterna de Coro, que denegándose a reconocer su legitimidad, la declaró insurgente, y la hostilizó como enemigo. La Junta Suprema en lugar de subyugar aquella indefensa ciudad, que estaba rendida con presentar nuestras fuerzas marítimas delante de su puerto, la dejó fortificar y tomar una actitud tan respetable que dejó subyugar después la confederación entera, con casi igual facilidad que la que teníamos nosotros anteriormente para vencerla, fundando la Junta su política en los principios de humanidad mal entendida que no autorizan a ningún gobierno para ser por la fuerza libres a los pueblos estúpidos que desconocen el valor de sus derechos (Bolívar, 1812, p. 5).

Las fuerzas de Monteverde se fortalecieron rápidamente y comenzaron a hacer estragos en la moral de los ejércitos patriotas, los cuales padecieron el rigor de las deserciones, ante lo cual Bolívar expresó más adelante en el escrito anteriormente mencionado: "El soldado bisoño lo cree todo perdido, desde que es derrotado una vez, porque la experiencia no le ha probado que el valor, la habilidad y la constancia corrigen la mala fortuna" (Bolívar, 1812, p. 2).

Experiencia de la que adolecía el propio Bolívar quien, ocupando la comandancia de la importante ciudad de Puerto Cabello, fue traicionado por uno de sus oficiales y derrotado por los prisioneros que custodiaba en su plaza, los cuales se tomaron uno de los fortines y destruyeron las fuerzas del novato Coronel. 
El 5 de julio de 1812 Bolívar salió rumbo al puerto de La Guaira con sus oficiales sobrevivientes, ciudad en la que se le unió al poco tiempo el propio Miranda quien, por orden del Congreso y ante la inminente derrota, suscribió el 26 de julio del mismo año el Tratado de La Victoria, mediante el que los ejércitos de la Primera República de Venezuela capitularon frente a las tropas de Monteverde.

Por segunda vez derrotado en territorio venezolano, Miranda llegó al puerto de La Guaira el 30 de julio, en donde lo esperaba un buque inglés que lo llevaría al extranjero. Sin embargo, sus oficiales Manuel María Casas, comandante de la plaza, Miguel Peña y Simón Bolívar, lo convencieron de que pernoctara al menos una noche más en el puerto, oportunidad que fue aprovechada por ellos mismos para desarmarlo y capturarlo mientras dormía, y entregárselo luego a los españoles.

Aunque no existe claridad acerca de los móviles de esta conducta que puede ser entendida como una flagrante traición, algunos historiadores afirman que Bolívar y sus compañeros se sintieron, a su vez, traicionados por Miranda al capitular, aun teniendo fuerzas suficientes para seguir luchando por la causa de la independencia.

Murió así la Primera República de Venezuela, de la que salió exiliado Simón Bolívar el 27 de agosto rumbo a Curazao, de donde pasó luego a Cartagena; mientras Miranda iniciaba su presidio en Puerto Cabello, ciudad de la que fue trasladado en 1813 a Puerto Rico, para finalmente llegar al Arsenal de la Carraca, cerca de Cádiz, donde murió el 14 de julio de 1816.

\section{Manifiesto de Cartagena}

Un Bolívar derrotado y aún inexperto en el arte de la guerra fue el que llegó a Cartagena a finales de 1812. Sin embargo, la crítica situación que atravesaba la ciudad en ese momento, propiciada por el bloqueo terrestre y fluvial que le habían impuesto las tropas realistas asentadas en Santa Marta y que le cortaban su vía de aprovisionamiento por el río Magdalena, fueron la coyuntura perfecta para que el Coronel venezolano fuese admitido en las filas cartageneras.

Encargado de guarecer la posición de Barrancas, en el bajo Magdalena, antes de partir, Bolívar publicó su Manifiesto de Cartagena, documento que podría ser resumido en tres grandes bloques: $1^{\circ}$ Evaluación y exposición de los motivos que, según él, propiciaron la caída de la Primera República de Venezuela;.$^{\circ}$ Exhortación al gobierno de las Provincias Unidas de la Nueva Granada, a no caer en los mismos errores cometidos en Venezuela, y $3 .^{\circ}$ Invitación a la reconquista de Venezuela, la cual presentaba Bolívar como una necesidad imperante para el gobierno de la Nueva Granada, dado que, en sus propias palabras: 
[...] poseyendo la España el territorio de Venezuela, podrá con facilidad sacarle hombres y municiones de boca y guerra, para que bajo la dirección de jefes experimentados contra los grandes maestros de la guerra, los franceses, penetren desde las Provincias de Barinas y Maracaibo hasta los últimos confines de la América meridional (Bolívar, 1812, p. 5).

Bolívar fue claro en su redacción y contundente en sus argumentaciones. Criticó la desunión de las provincias venezolanas, la misma que fue propiciada en su concepto por el sistema federalista, al que hizo alusión de la siguiente manera: "Pero lo que debilitó más el Gobierno de Venezuela fue la forma federal que adoptó, siguiendo las máximas exageradas de los derechos del hombre que, autorizándolo para que se rija por Sí mismo, rompe los pactos sociales y constituye a las naciones en anarquía" (Bolívar, 1812, p. 3).

\section{Para el Coronel venezolano:}

[...] El sistema federal, bien que sea el más perfecto y más capaz de proporcionar la felicidad humana en sociedad, es, no obstante, el más opuesto a los intereses de nuestros nacientes estados. Generalmente hablando, todavía nuestros conciudadanos no se hallan en aptitud de ejercer por Sí mismos y ampliamente sus derechos; porque carecen de las virtudes políticas que caracterizan al verdadero republicano; virtudes que no se adquieren en los gobiernos absolutos, en donde se desconocen los derechos y los deberes del ciudadano (Bolívar, 1812, p. 3).

Bolívar se mostraba partidario entonces de tener gobiernos fuertes que hicieran frente a las circunstancias, como lo dejó en claro más adelante:

[...] Es preciso que el Gobierno se identifique, por decirlo así, con el carácter de las circunstancias, de los tiempos y de los hombres que lo rodean. Si éstos son prósperos y serenos, él debe ser dulce y protector; pero si son calamitosos y turbulentos, él debe mostrarse terrible y armarse de una firmeza igual a los peligros, sin atender a las leyes, ni constituciones, ínterin no se restablece la felicidad y la paz (Bolívar, 1812, p. 3).

El futuro Libertador criticaba, además, las elecciones populares y a los partidos, contra los que arremetió en duros términos:

[...] Las elecciones populares hechas por los rústicos del campo y por los intrigantes moradores de las ciudades, añaden un obstáculo más a la práctica de la federación entre nosotros, porque los unos son tan ignorantes que hacen sus votaciones maquinalmente, y los otros tan ambiciosos que todo lo convierten en facción; por lo que jamás se vio en Venezuela una votación libre y acertada, lo que ponía al gobierno en manos de hombres ya desafectos a la causa, ya ineptos, ya inmorales. El espíritu de partido decidía en todo, y por consiguiente nos desorganizó más de lo que las circunstancias hicieron. Nuestra división, y no las armas españolas, nos tornó a la esclavitud (Bolívar, 1812, p. 4).

Esta oposición a las elecciones abiertamente populares fue uno de los puntos recurrentes no solo de este joven Bolívar, sino de los nuevos gobiernos ameri- 
canos que fueron surgiendo a lo largo y paulatino proceso de Independencia, los cuales optaron en su mayoría por elecciones de tipo censitario, en las que se limitaba el derecho de participación a las personas con poder económico y con niveles mínimos de educación, lo que pretendía garantizar el bien de la nación, ante el riesgo de que las grandes masas 'ignorantes' fuesen un factor disociador del juego político.

Para Bolívar la caída de la Primera República Venezolana y los problemas anteriormente mencionados se debían, en gran medida, a la inexperiencia de sus gobernantes y a que:

[...] Los códigos que consultaban nuestros magistrados no eran los que podían enseñarles la ciencia práctica del Gobierno, sino los que han formado ciertos buenos visionarios que, imaginándose repúblicas aéreas, han procurado alcanzar la perfección política, presuponiendo la perfectibilidad del linaje humano. Por manera que tuvimos filósofos por jefes, filantropía por legislación, dialéctica por táctica, y sofistas por soldados. Con semejante subversión de principios y de cosas, el orden social se sintió extremadamente conmovido, y desde luego corrió el Estado a pasos agigantados a una disolución universal que bien pronto se vio realizada (Bolívar, 1812, p. 1) ${ }^{13}$.

El caraqueño no olvidó en ese momento su rol como militar por lo que en la última sección de su Manifiesto, advirtió que si no se actuaba en contra de los españoles que nuevamente ocupaban Venezuela:

[...] Estos tránsfugos hallarán ciertamente una favorable acogida en los puertos de Venezuela, como que vienen a reforzar a los opresores de aquel país y los habilitan de medios para emprender la conquista de los estados independientes.

Levantarán quince o veinte mil hombres que disciplinarán prontamente con sus jefes, oficiales, sargentos, cabos y soldados veteranos. A este ejército seguirá otro todavía más temible de ministros, embajadores, consejeros, magistrados, toda la jerarquía eclesiástica y los grandes de España, cuya profesión es el dolo y la intriga, condecorados con ostentosos títulos, muy adecuados para deslumbrar a la multitud; que derramándose como un torrente, lo inundará todo arrancando las semillas y hasta las raíces del árbol de la libertad de Colombia. Las tropas combatirán en el campo; y éstos, desde sus gabinetes, nos harán la guerra por los resortes de la seducción y del fanatismo (Bolívar, 1812, p. 6).

A partir de la lectura del Manifiesto de Cartagena, se hace evidente el encono que despertaban en Bolívar los españoles, los cuales pronto serían condenados por él al exterminio, tras la expedición del Decreto de Guerra a Muerte o Decreto de Trujillo que abordaremos más adelante.

Frente al peligro que para él significaba la cercanía de las tropas realistas, Bolívar planteaba la urgencia de una guerra ofensiva afirmando: “... es un prin-

$1 \quad$ Las negrillas son nuestras. 
cipio del arte que toda guerra defensiva es perjudicial y ruinosa para el que la sostiene; pues lo debilita sin esperanza de indemnizarlo; y que las hostilidades en el territorio enemigo siempre son provechosas, por el bien que resulta del mal del contrario..." (Bolívar, 1812, p. 6).

Por último, Bolívar vaticinaba en su escrito el éxito en las acciones militares, aduciendo que la guarnición española era débil y no gozaba del respaldo popular:

[...] Debemos considerar también el estado actual del enemigo, que se halla en una posición muy crítica, habiéndoseles desertado la mayor parte de sus soldados criollos [...] De modo que no sería imposible que llegasen nuestras tropas hasta las puertas de Caracas, sin haber dado una batalla campal (Bolívar, 1812, pp. 6-7).

Al final de su Manifiesto y dando muestras de lo que fue su contundente estilo a lo largo de su vida política, remató con una exaltación, elemento que recurrentemente utilizó a lo largo de sus textos posteriores:

[...] Corramos a romper las cadenas de aquellas víctimas que gimen en las mazmorras, siempre esperando su salvación de vosotros; no burléis su confianza; no seáis insensibles a los lamentos de vuestros hermanos. Id veloces a vengar al muerto, a dar vida al moribundo, soltura al oprimido, y libertad a todos (Bolívar, 1812, p. 7).

Bolívar aún no salía de Cartagena y ya estaba trazando las líneas de la que pasaría a la historia como la 'Campaña Admirable', en la que nos detendremos más adelante. Sin embargo, es claro que aquel Coronel venezolano, admitido por el gobierno cartagenero bajo la consigna de 'limpiar de piratas realistas' el Bajo Magdalena y asegurar la posesión del poblado de Barranca, no tenía intenciones de permanecer mucho tiempo bajo esa bandera y con esa estrecha jurisdicción.

\section{Campaña del Bajo Magdalena}

Para entender las dimensiones de esta campaña, es importante citar las palabras del Presidente de la Academia Colombiana de Historia Militar, Mayor General José Roberto Ibáñez, al respecto:

[...] No era Bolívar un soldado que pudiera someterse al combate limitado en tiempo, en espacio y en proporción militar, menos aún a permanecer pasivamente, mirando de lejos al enemigo y subordinado a un jefe extranjero. Su gloria militar surgió de un acto de desobediencia a unas órdenes estáticas e inoperantes que en la guerra no producen resultados. Al mando de su fuerza, que apenas superaba el centenar de hombres sin experiencia de combate, realizó algunas incorporaciones hasta elevarla a 200 y llegó a Barranca el 1 de diciembre de 1812, donde en solo tres semanas logró entrenarla y disciplinarla para formar una unidad para el combate (Ibáñez, 2014). 
Fue así como a pesar de que su superior directo, el oficial francés Pierre Labatut (quien había hecho parte también de las huestes que pelearon al lado de Miranda en la Primera República Venezolana) le asignó la defensa del pueblo de Barranca; Bolívar comenzó con energía sus acciones militares, dando pie a la que se conocería como la Campaña del Bajo Magdalena, primera operación militar exitosa que dirigió el futuro Libertador, responsable de que su nombre comenzara a ser tenido en cuenta entre los militares destacados al servicio de la independencia en el territorio de la Nueva Granda.

Tras tomarse Tenerife el 23 de diciembre de 1813, plaza fuerte de los realistas de Santa Marta en el margen derecho del río Magdalena, Bolívar logró ingresar victorioso a Mompox el 27 de diciembre, rompiendo el bloqueo que se mantenía sobre Cartagena y liberando de realistas la región. Acción militar que le dio renombre y de la que surgió una frase adjudicada a Bolívar, que la historiografía patria ha inmortalizado: "si a Caracas debo la vida, a Mompox debo la gloria".

Desobedeciendo las órdenes dadas en Cartagena, pero inspirado y animado por sus triunfos, Bolívar dejó así el río Magdalena y capturó la ciudad de Ocaña, donde recibió la solicitud de apoyo que le envió el Coronel del gobierno de las Provincias Unidas de la Nueva Granada, Manuel del Castillo, quien lo invitaba a que atacaran en conjunto a las tropas del Coronel realista Ramón Correa que se encontraban acantonadas en Cúcuta.

Bolívar solicitó en ese momento la autorización a Cartagena y, una vez obtenida esta, aceptó el llamado de Castillo. El combate tuvo lugar el 28 de febrero de 1813, y fue una derrota para los realistas, quienes tuvieron que refugiarse en Venezuela, dejando en el campo su artillería. El caraqueño estaba justo en la frontera, pero decidió solicitar autorización antes de emprender acciones en 'territorio extranjero', por lo que envió un emisario a Tunja y a Santafé para pedirles autorización al Congreso y a Nariño, quienes le respondieron no solo con la autorización, sino que le confirieron el título de ciudadano de la Nueva Granada, ascendiéndolo, además, a Brigadier de los Ejércitos de la Unión y General en Jefe del Ejército del Norte y, además, le enviaron auxilios representados en oficiales, tropa y armas.

Entre las fuerzas que se le unieron a Bolívar, se destacaban muchos de los oficiales neogranadinos que pasaron a la historia por el valor y coraje demostrado en el curso de la Campaña Admirable: Atanasio Girardot, Antonio Ricaurte, Luciano D'elhúyar, Hermógenes Maza, Joaquín París y Francisco de Paula Vélez. Fue en medio de esta gesta militar, en la que apareció el tercer documento que analizaremos: el Decreto de Guerra a Muerte. 


\section{Decreto de Guerra a Muerte}

No todo iba a ser fácil para Bolívar, quien en pocos meses había pasado de ser un Coronel derrotado y desconocido en la Nueva Granada, a un General reputado y victorioso a quien se le entregó el mando supremo del Ejército del Norte. El Coronel Castillo, el mismo que lo había invitado a concurrir a Cúcuta para enfrentar en conjunto a las tropas de Correa, entró en disputa con el caraqueño, se retiró con las tropas a su mando hacia Bogotá, y debilitó la fuerza con la que Bolívar pasó después a Venezuela.

De igual manera el joven Santander, para ese entonces Sargento Mayor (graduación equivalente a Mayor en el presente), tuvo un fuerte enfrentamiento con Bolívar, el que por poco pasa a un hecho de armas. Al final los ánimos se calmaron y las tropas pasaron a Venezuela; y Santander quedó al cuidado de Cúcuta y de la retaguardia de las tropas expedicionarias.

La Campaña inició con éxitos rápidos y significativos; Bolívar entró triunfante a Mérida el 23 de mayo de 1823, ciudad en la que se le llamó por primera vez Libertador, título que adoptaría para sí, y que prefirió sobre los demás que recibió a lo largo de su carrera. Tras la captura por parte de las tropas al mando de Atanasio Girardot de la ciudad de Trujillo el 9 de junio, Bolívar se trasladó a esta población donde el 15 de junio publicó su Decreto de Guerra a muerte en el que afirmó:

[...] Nosotros somos enviados a destruir a los españoles, a proteger a los americanos, y a restablecer los gobiernos republicanos que formaban la Confederación de Venezuela (Bolívar, 1813, p. 1).

Las noticias de las represalias realistas en contra de los antiguos partidarios de la república y los ya mencionados temores de Bolívar acerca de la influencia negativa que ejercían los peninsulares sobre las masas, los cuales describía en su ya tratado Manifiesto de Cartagena (Bolívar, 1812, p. 6) ${ }^{24}$, lo llevaron a tomar medidas radicales.

Bolívar estaba dispuesto a sembrar el terror entre los españoles y a cumplir una venganza que expone en los siguientes términos:

[...] Así pues, la justicia exige la vindicta, y la necesidad nos obliga a tomarla. Que desaparezcan para siempre del suelo colombiano los monstruos que lo infestan y han cubierto de sangre; que su escarmiento sea igual a la enormidad de su perfidia, para lavar de este modo la mancha de nuestra ignominia, y mostrar a las naciones del universo, que no se ofende impunemente a los hijos de América" (Bolívar, 1813, p. 1).

2 Ver cita completa en el apartado del Manifiesto de Cartagena Bolívar. 
La sentencia era clara: "Todo español que no conspire contra la tiranía en favor de la justa causa, por los medios más activos y eficaces, será tenido por enemigo, y castigado como traidor a la patria y, por consecuencia, será irremisiblemente pasado por las armas" (Bolívar, 1813, p. 2). Por el contrario, el ahora conocido como Libertador les daba amplias garantías a los americanos, las cuales expuso de manera complaciente:

[...] Y vosotros, americanos, que el error o la perfidia os ha extraviado de las sendas de la justicia, sabed que vuestros hermanos os perdonan y lamentan sinceramente vuestros descarríos, en la íntima persuasión de que vosotros no podéis ser culpables, y que solo la ceguedad e ignorancia en que os han tenido hasta el presente los autores de vuestros crímenes, han podido induciros a ellos. No temáis la espada que viene a vengaros y a cortar los lazos ignominiosos con que os ligan a su suerte vuestros verdugos (Bolívar, 1813, p. 2).

Para entender ese despliegue de 'generosidad' que se extendía incluso a "... los mismos traidores que más recientemente hayan cometido actos de felonía..." (Bolívar, 1813, p. 2), es importante entender que España aún se encontraba invadida por los ejércitos napoleónicos, con los que libraba una cruenta contienda en la península, lo que hacía que el grueso de las tropas que militaban en el bando realista en Venezuela fuesen criollos y mestizos a los que Bolívar trata de incorporar por este medio a sus fuerzas o al menos garantizar una esperada neutralidad por parte de las comunidades que, si bien no eran afectas a la emancipación, no verían con temor la llegada de las tropas bolivarianas, lo que actuaría a favor de sus contrarios.

Bolívar comenzó a traducir en hechos los apuntes consignados en el Manifiesto de Cartagena, cuando abogaba por un gobierno fuerte que estuviera a tono con las circunstancias y características del conflicto, pues, como él mismo lo afirmó desde Cartagena: "El más consecuente error que cometió Venezuela al presentarse en el teatro político fue, sin contradicción, la fatal adopción que hizo del sistema tolerante; sistema improbado como débil e ineficaz..." (Bolívar, 1812, p. 1).

Volviendo al tema de las contundentes sentencias que caracterizaban la conclusión de los escritos de Bolívar, en este caso el mensaje fue muy claro: "Españoles y Canarios, contad con la muerte, aun siendo indiferentes, si no obráis activamente en obsequio de la libertad de América. Americanos, contad con la vida, aun cuando seáis culpables" (Bolívar, 1813, p. 2).

\section{Bolívar y la 2.a República venezolana}

La publicación del Decreto de Guerra a Muerte antecedió a un avance importante de las tropas de Bolívar que el 31 de julio vencieron a los realistas en la 
Batalla de Tinajillo, forzaron a Monteverde a refugiarse en la fortificada ciudad de Puerto Cabello, y le dejaron el paso franco a Bolívar, quien llegó triunfante a Caracas el 6 de agosto de 1813; así se dio inicio al corto período de existencia de la que pasó a conocerse como la Segunda República de Venezuela.

Sin embargo, Bolívar estaba lejos de disfrutar tranquilamente de las mieles del poder como presidente de Venezuela. Las sitiadas fuerzas de Puerto Cabello no cesaban de hostilizar a las patriotas, propiciando batallas como la de El Bárbula, en la que murió el coronel granadino Atanasio Girardot el 30 de septiembre de 1813 o la de Las Trincheras, que coronó con gloria el ascenso a coronel de Luciano D'elhúyar el 3 de octubre del mismo año.

La situación de Bolívar se complicó aún más con la aparición en el escenario bélico del coronel español José Tomás Boves, quien después de vencer a las tropas al mando del patriota español Vicente Campo Elías en la Primera Batalla de La Puerta el 3 febrero de 1814, comenzó a hostigar las fuerzas venezolanas en los Llanos de Araguá, lo que propició inicialmente las batallas de La Victoria (14 de febrero de 1814) y San Mateo (del 28 de febrero al 25 de marzo de 1814), ambas con triunfo patriota.

Estas fueron victorias pírricas ante la imposibilidad de Bolívar de frenar el empuje de las fuerzas de Boves, las cuales lo derrotaron en la Segunda Batalla de La Puerta el 15 de junio de 1814, que dejó el terreno prácticamente libre para que Boves llegara el 16 de julio a Caracas, ciudad de la que el 6 de julio salieron evacuadas vía marítima más de 20.000 personas, rumbo a las provincias del oriente venezolano, ante el temor de ser pasados por las armas.

\section{A modo de conclusión}

Una vez evacuada Caracas, el Decreto de Guerra a Muerte expedido por El Libertador, actuaba ahora en contra de él mismo, sus tropas y los civiles afectos a su causa, quienes encontraron en Boves un enemigo que los acosaba y destruía sin cuartel, mientras avanzaban hacia el oriente venezolano.

Bolívar renunció el 7 de julio a su cargo de presidente, pero continuó desarrollando acciones militares ahora en compañía del General José Francisco Bermúdez, uno de los principales caudillos del oriente de Venezuela, junto a quien fue nuevamente derrotado en la Araguá de Barcelona el 17 de agosto, con gravísimas pérdidas entre civiles y militares para los patriotas.

Para Bolívar el sueño de una Segunda República de Venezuela había terminado y se aprestaba a partir derrotado de nuevo hacia la Nueva Granada, dejando tras de sí la sangre de gran parte de los militares que lo acompañaron al 
inicio de la Campaña Admirable. Seguirían a continuación años particularmente aciagos para El Libertador, pero en los que salió a flote el peso de su pluma y la tenacidad política y militar que lo llevaron a coronar con éxito sus metas.

\section{Referencias bibliográficas}

Bolívar, S. Carta de Jamaica (6 de septiembre de 1815). En Simón Bolívar: 200 años de vigencia y memoria (2015). Medellín: Universidad de Antioquia.

Bolívar, S. (1813). Decreto de Guerra a Muerte (15 de junio de 1813). Transcripción digitalizada. En www.analitica.com/bitblio/bolivar/decreto.asp

Bolívar, S. (1816). Decreto de libertad absoluta para los esclavos (2 de junio de 1816). Transcripción digitalizada. En www.rena.edu.ve/TerceraEtapa/Historia/PartBolivarAbEsclavitud.html

Bolívar, S. (1986 [1819]). Discurso de Angostura (15 de febrero de 1819). Transcripción digitalizada. En Ideas en torno de Latinoamérica. Edición de Leopoldo Zea. México: UNAM.

Bolívar, S. (1805). Juramento de Roma (15 de agosto de 1805). Transcripción digitalizada. En http:// es.wikisource.org/wiki/Juramento _ de _ Roma

Bolívar, S. (1812). Manifiesto de Cartagena (15 de diciembre de 1812). Transcripción digitalizada. En http://es.wikisource.org/wiki/Manifiesto _ de _Cartagena

Bolívar, S. (1814). Manifiesto de Carúpano (7 de septiembre de 1814). Transcripción digitalizada. En http://es.wikisource.org/wiki/Manifiesto _ de _ Car\%C3\%BApano

Ibáñez, J. R. (2014). El río Magdalena en la Guerra de Independencia. En Credencial Historia $\mathrm{N}^{\circ} 291$, Bogotá.

Liévano Aguirre, I. (2007). Bolívar. Caracas: Grijalbo.

Malagón Pinzón, M. (2007). El pensamiento republicano de Bolívar en el proyecto constitucional de Angostura de 1819 y en la Constitución de 1826. En Revista de Derecho N. ${ }^{\circ}$ 27, Barranquilla, pp. 98-133.

Miranda, Francisco de (1806). Proclamación de Don Francisco de Miranda, Comandante-General del Exército Colombiano, á los pueblos habitantes del Continente Americo-Colombiano. En Gutiérrez Escudero, Antonio (2006). Francisco de Miranda y su expedición libertadora de 1806. Sevilla (España): Escuela de Estudios Hispano-Americanos, CSIC

Uribe Ángel, M. (1884). El Libertador, su ayo y su capellán. En Homenaje de Colombia al Libertador Simón Bolívar en su Primer Centenario, 1783-1883 (pp. 72-74). Bogotá: Edición Oficial. 
